\title{
Representações gráficas de síntese como ferramenta de apoio à compreensão dos conteúdos de Design da Informação
}

\author{
Graphic Representations for Synthesis (GRS) as a tool to support the \\ understanding of Information Design contents.
}

Fernanda Pereira Corrêa da Silva; Michelle Pereira de Aguiar

representações gráficas de síntese; pensamento visual; aprendizagem; teoria dos signos.

Representações Gráficas de Síntese são importantes ferramentas práticas no aprendizado e ensino de todas as áreas do conhecimento. A partir das teorias da Psicologia Cognitiva e Teorias de Aprendizagem, compreende-se como otimizar processos mentais com ferramentas de visual thinking, visual learning e visual communication. Para este artigo, articulam-se elementos de representação visual em níveis sintático, semântico e pragmático para analisar as amostras produzidas em aula por alunos dos cursos de Design e Design Visual e verificar como o pensamento de síntese gráfica é formalizado na síntese de informações.

graphic representations of synthesis; visual thinking; learning; theory of signs.

Graphic Representations of Synthesis are relevant practical tools in the learning and teaching of every expertise area. Approaching theories of Cognitive Psychology and Learning Theories, it is possible to understand how to optimize mental processes using visual thinking, visual learning and visual communication tools. Elements of visual representation are articulated in the syntactic, semantic and pragmatic levels to analyze samples developed by Visual Design students and comprehend the formalization of graphical synthesis thought on information synthesys.

\section{Introdução}

O pensamento visual permite organizar e realizar conexões entre dados, informações e ideias para melhorar a capacidade de pensar e comunicar, criar estratégias; compartilhar, descobrir e organizar ideias; resolver problemas; analisar e interpretar dados; descrever conceitos complexos; sintetizar informações; compreender e memorizar. Partindo da disciplina de Design da Informação dos cursos de Design da Universidade Positivo, este artefato é utilizado como recurso adicional para exercícios e fixação de conteúdos desde 2016. No entanto, parte dos alunos demonstra dificuldade em reconhecer seus elementos para representação das informações.

A partir do exposto, tem-se a pergunta: como as representações gráficas de síntese podem ser utilizadas para ilustrar o pensamento visual e auxiliar o aluno dos cursos de Design na representação dos conteúdos da disciplina de Design da Informação? Como estratégia, buscou-se identificar elementos da sintaxe, semântica e pragmática para ilustrar

Anais do $10^{\circ} \mathrm{CIDI}$ e $10^{\circ} \mathrm{CONGIC}$

Kelli C.A.S. Smythe, Rafael de Castro Andrade (orgs.)

Sociedade Brasileira de Design da Informação - SBDI

Curitiba | Brasil | 2021
Proceedings of the $10^{\text {th }} \mathrm{CIDI}$ and $10^{\text {th }}$ CONGIC

Kelli C.A.S. Smythe, Rafael de Castro Andrade (orgs.)

Sociedade Brasileira de Design da Informação - SBDI Curitiba | Brazil | 2021 
o pensamento visual do aluno, cujos resultados são discutidos e apresentados a seguir, a partir de um levantamento de dados, seguido pela condução da pesquisa e consequente discussão dos resultados.

\section{Psicologia Cognitiva e Teorias de Aprendizagem}

Considerado o Design da Informação como área do Design dedicada ao estudo das variáveis envolvidas na percepção e comunicação de uma mensagem eficaz, percebe-se sua responsabilidade - enquanto disciplina - ao compor layouts informativos a partir do planejamento, organização e formatação dos conteúdos de uma mensagem, considerando emissor, receptor da mensagem e o contexto da mensagem (IIID, 1997 apud Pettersson, 2002, p.18). Dentre as premissas desta disciplina, tem-se a compreensão das necessidades do usuário, envolvendo-o como sujeito participante para assegurar que a mensagem será absorvida precisamente (Mullet \& Sano, 1995 apud Pettersson, 2002).

Assim, para criar materiais informativos, faz-se necessário compreender as maneiras como o processamento da informação e o aprendizado ocorrem na mente humana. Neves (2006) expõe que a psicologia cognitiva busca entender maneiras de pensar, interpretar e perceber o mundo com base nas teorias piagetianas, neopiagetianas, teoria de Vygotsky e abordagem do processamento da informação. Segundo Neves, as bases para a cognição propostas Piaget são estruturadas em etapas de desenvolvimento da inteligência conforme a idade do sujeito. Teóricos neopiagetianos enfatizam como esses processos são utilizados na organização, segregação e diferenciação de informações para atingir objetivos e metas. Com isso, tais teorias utilizam a teoria do processamento da informação através de modelos mentais, como esquemas, planos e roteiros. Já a Teoria da Aprendizagem Significativa de David Ausubel exposta por Masini (2011) indica que a construção do conhecimento envolve a compreensão, reflexão e construção de significados individuais, em interação com o meio sociocultural.

O processamento da informação "ocorre quando um novo conteúdo retido de forma visual e fonética na memória de trabalho é integrado" (Clark \& Lyons, 2010 apud Padovani, 2012, p. 43). Padovani (2012) expõe que o visual thinking (mentalização imagética de conceitos) é utilizado para produzir representações gráficas e, por meio do pensamento visual e de sua representação gráfica tem-se aprendizado visual. Tal recurso possibilita a estruturação e validação de conceitos pelo levantamento, análise, síntese e reformulação de dados.

Adicionalmente, a capacidade de comunicar os conceitos absorvidos é denominada comunicação visual por um processo de ensino-aprendizagem, que envolve diretamente o aluno caracterizando uma aprendizagem ativa (Padovani, 2012).

\section{Representações Gráficas De Síntese}

De acordo com Padovani (2012), representações gráficas de síntese (RGSs) são ferramentas cognitivas artificiais para separar, organizar, categorizar, ressaltar e também sintetizar informações (Padovani, 2012, p.132). As representações devem conter pouco conteúdo textual 
e dar atenção a elementos pictóricos e esquemáticos. Elementos tipográficos são organizados em níveis hierárquicos por agrupamento, diferenciação de caixa e variação de tipo. $O$ modo pictórico bidimensional facilita os processos cognitivos e, para tanto, são utilizados containers e conectores (setas, caixas e linhas), aplicando cores moderadamente. Ademais, o uso de analogias e metáforas resultam em informação clara e atrativa (Bueno et al., 2020, p.144).

Para avaliar sintaticamente uma RGS, os estudos de Engelhardt (1996) auxiliam na categorização de objetos, espaços e propriedades gráficas (Tabela 1).

Tabela 1: Categorias sintáticas de objetos gráficos (Engelhardt, 2017, p. 276).

\begin{tabular}{|c|c|c|}
\hline $\begin{array}{l}\text { Categorias sintáticas } \\
\text { de objetos gráficos: }\end{array}$ & Tipos de anexos: & Exemplo(s): \\
\hline nó & marcas & $\begin{array}{l}\text { ponto marcando uma cidade no } \\
\text { mapa }\end{array}$ \\
\hline rótulo & objeto gráfico rotulado & $\begin{array}{l}\text { nome rotulando um objeto no } \\
\text { mapa }\end{array}$ \\
\hline conector & dois objetos gráficos conectados & $\begin{array}{l}\text { linha conectando dois nomes } \\
\text { em árvore genealógica }\end{array}$ \\
\hline linha de localização & $\begin{array}{l}\text { linha específica significativa no espaço } \\
\text { gráfico }\end{array}$ & linha no mapa (rio) \\
\hline superfície de localização & $\begin{array}{l}\text { superfície específica significativa no } \\
\text { espaço gráfico }\end{array}$ & $\begin{array}{l}\text { superfície colorida no mapa } \\
\text { (lago ou país) }\end{array}$ \\
\hline marcador de grid & linhas e marcações de orientação & linhas de latitude/longitude \\
\hline segmento proporcional & segmento de superfície do objeto gráfico & $\begin{array}{l}\text { segmento de círculo no gráfico } \\
\text { de pizza }\end{array}$ \\
\hline moldura & objeto gráfico emoldurado $\mathrm{p}$ & $\begin{array}{l}\text { plano que envolve uma caixa de } \\
\text { diálogo na } \mathrm{HQ}\end{array}$ \\
\hline
\end{tabular}

$\mathrm{Na}$ Tabela 1, observa-se que os elementos para compor uma representação gráfica delimitam conexão, separação, destaque, posição espacial, proporção e hierarquia da informação. Porém, este estudo ainda considera como base de análise o modelo LATCH de Wurman (1996 apud Rendgen, 2012) e o modelo LOTCH, proposto por Alves e Aguiar (2017, p. 278). O primeiro apresenta a organização por critérios de Localização, Alfabeto, Tempo, Categorias e Hierarquia. Já no segundo (Figura 1), substitui o conceito Alfabeto por Ordenação da informação (Alves \& Aguiar, 2017, p. 278). 
Figura 1: Modelo LOTCH (Alves \& Aguiar, 2017).

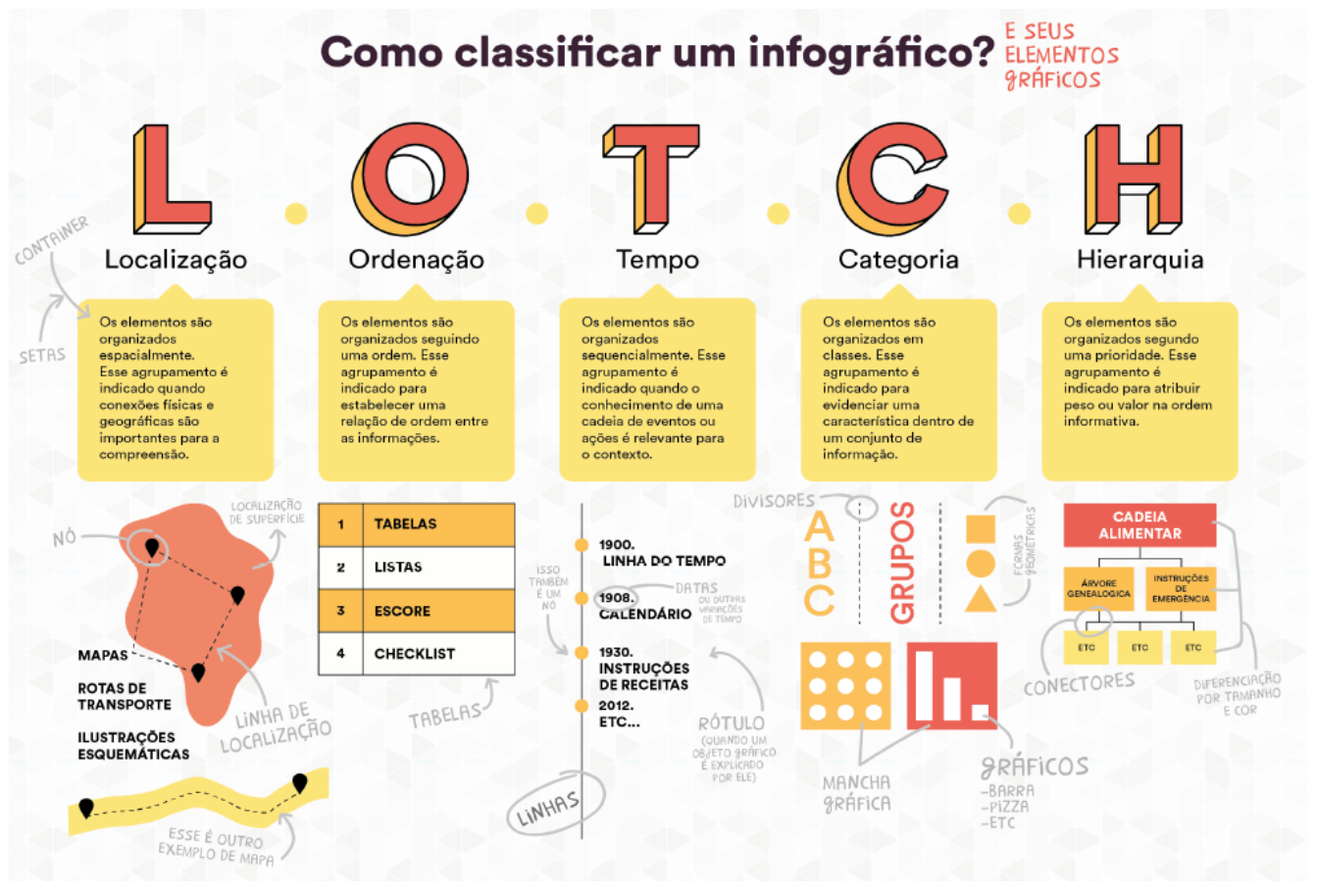

\section{Resultados e discussão}

Para as análises, foram selecionadas cinco dentre aproximadamente 230 amostras de representações gráficas de síntese desenvolvidas por alunos da disciplina de Design da Informação nos cursos de Design da Universidade Positivo, entre 2016 e 2017. E, para seleção de amostras, elencaram-se os seguintes critérios:

- Presença de container;

- Presença de conectores;

- Simplicidade semântica;

- Presença de ilustrações;

- Organização hierárquica das informações.

Assim, as amostras selecionadas foram: 
Figura 2: Amostra 1 (RGS sobre aumento da tarifa do transporte em Curitiba).
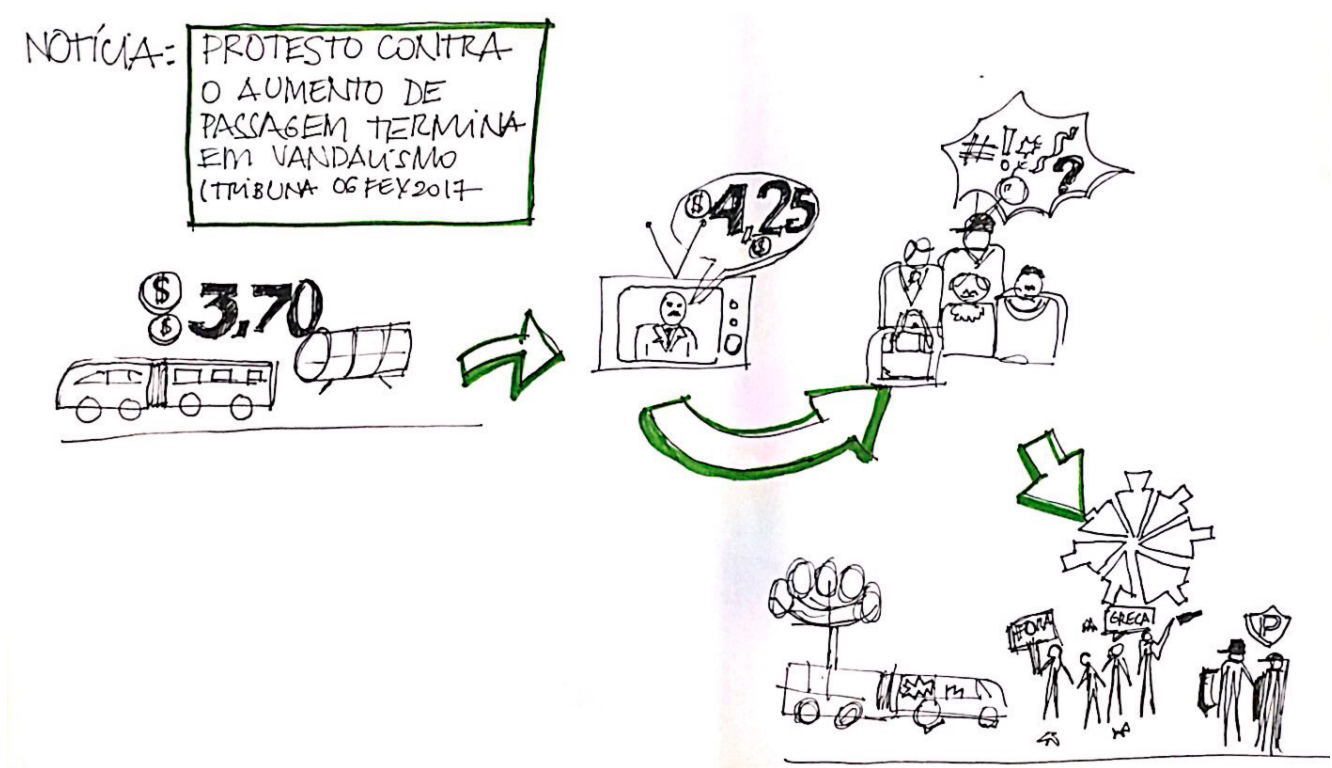

Figura 3: Amostra 2 (RGS sobre aumento da tarifa do transporte em Curitiba).

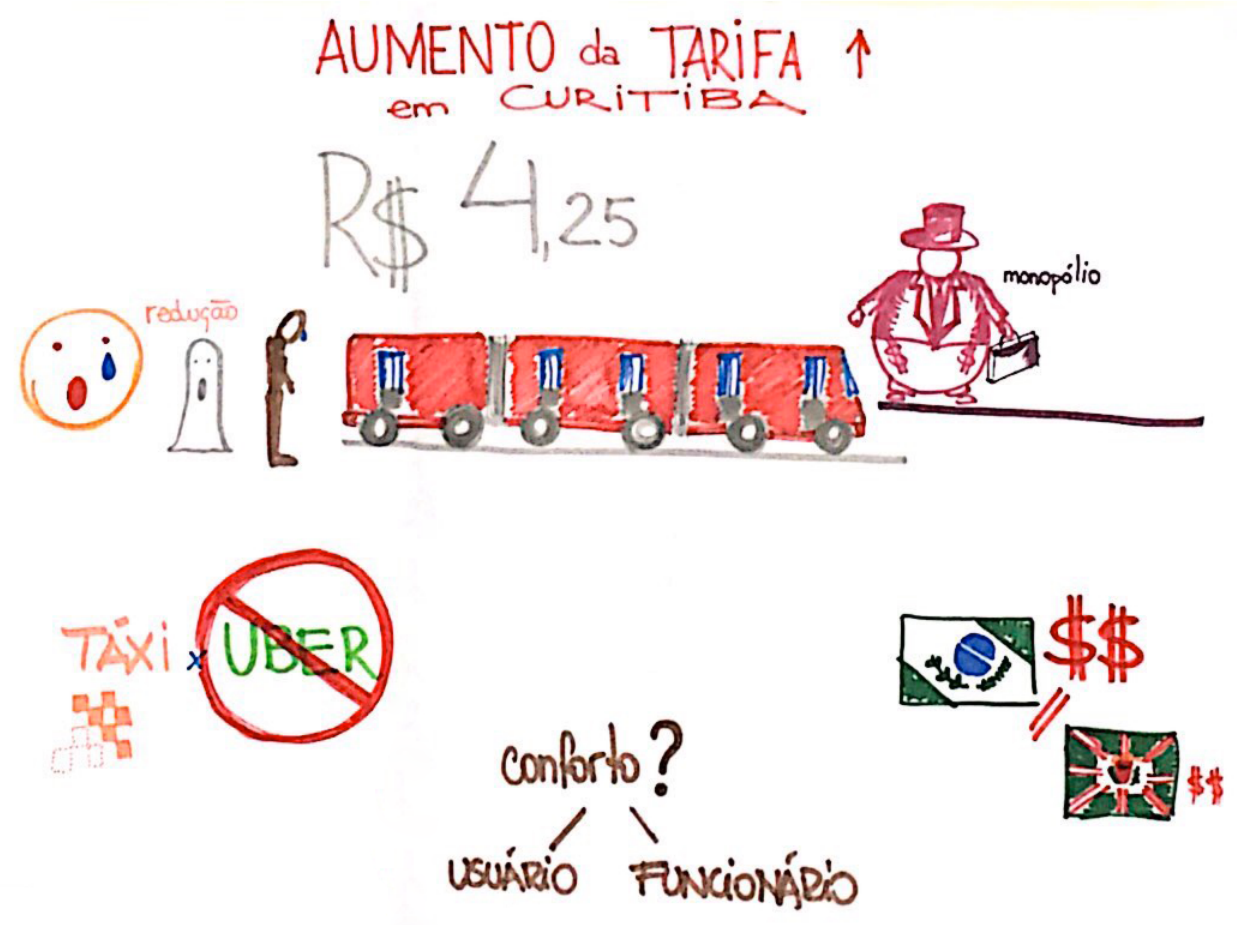


Figura 4: Amostra 3 (RGS sobre artigo Infodesign 2005).

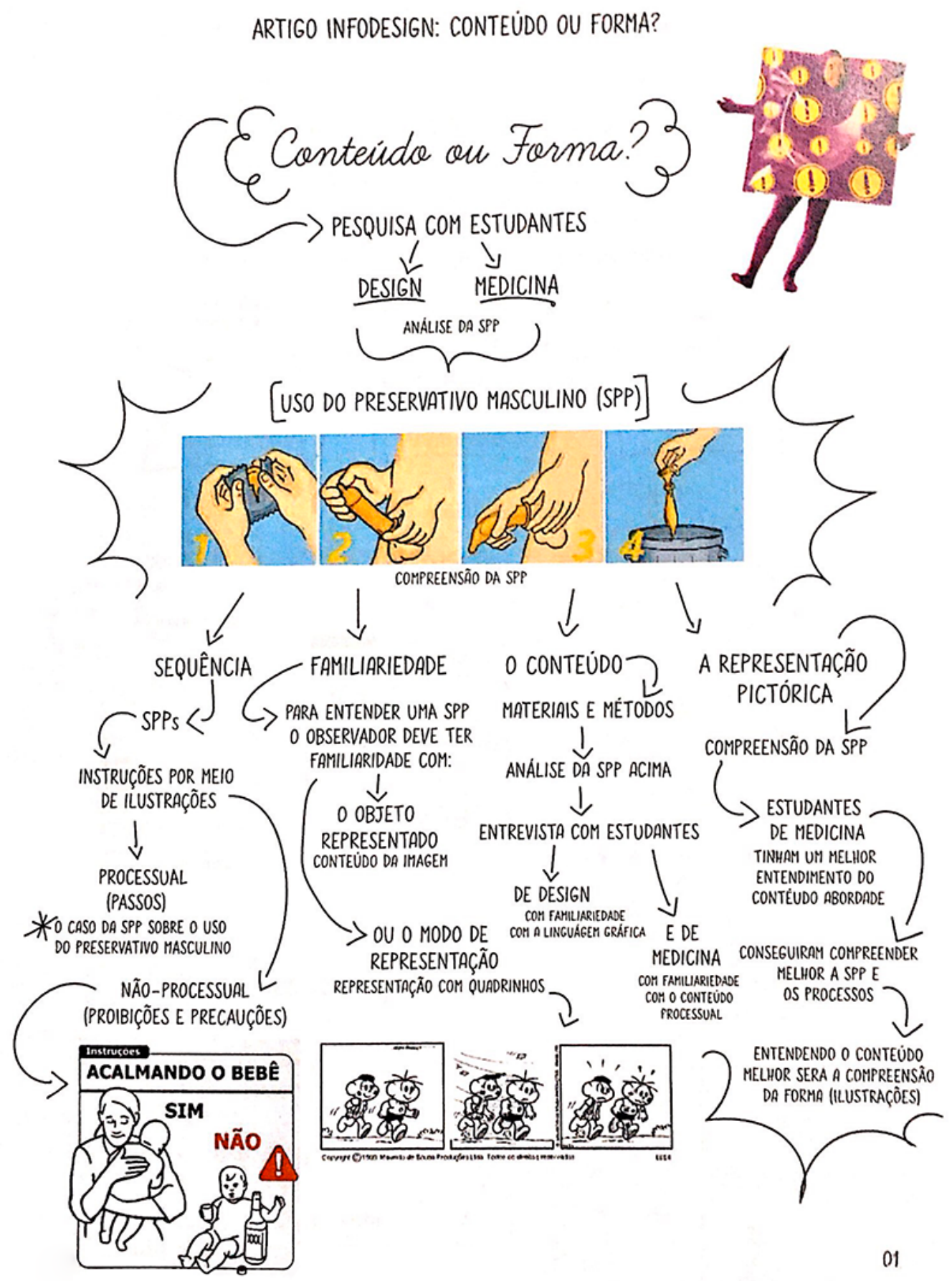


Figura 5: Amostra 4 (RGS sobre Design Digital).

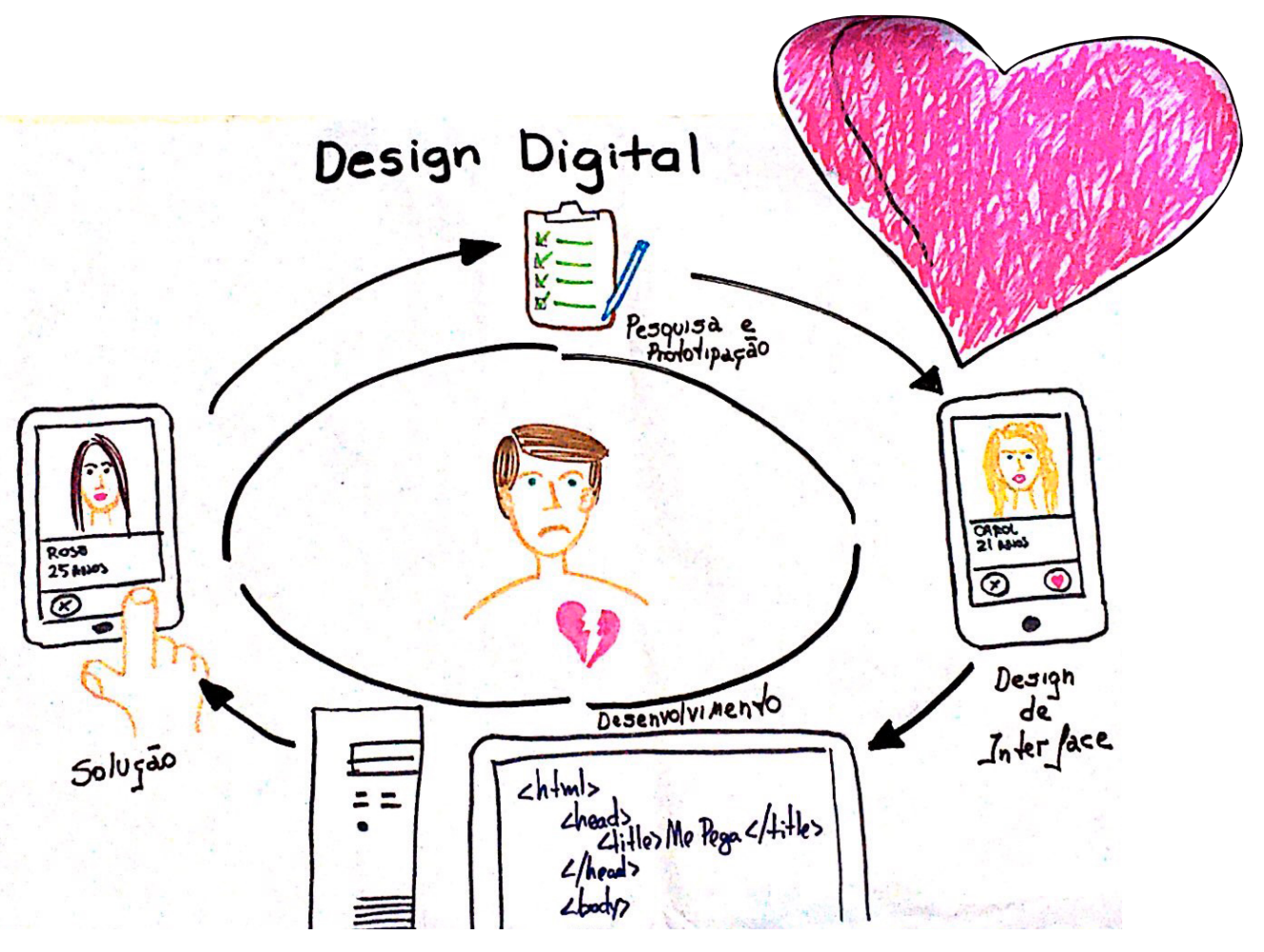

Figura 6: Amostra 5 (RGS sobre Sistemas de Sinalização e Wayfinding).

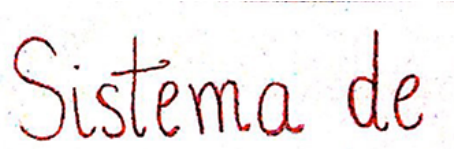

Sinalização

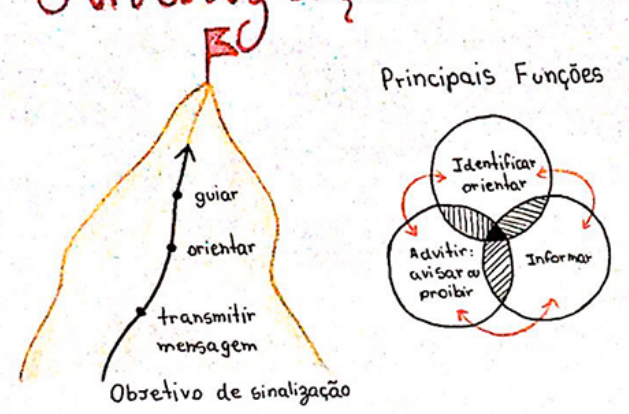

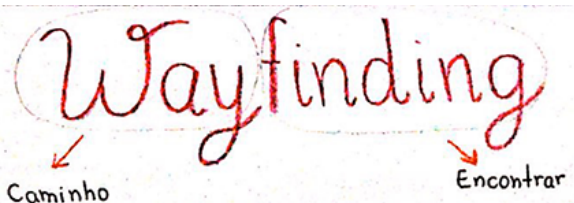

[0] Orientação

[v]. Encontrar caminho/destino

[v] Localizar-se

[v Processo cognitivo $\rightarrow$ vexo $\rightarrow$ penso

[7] AJuda o usuário a resolver problemas

[v] Ponto de referência

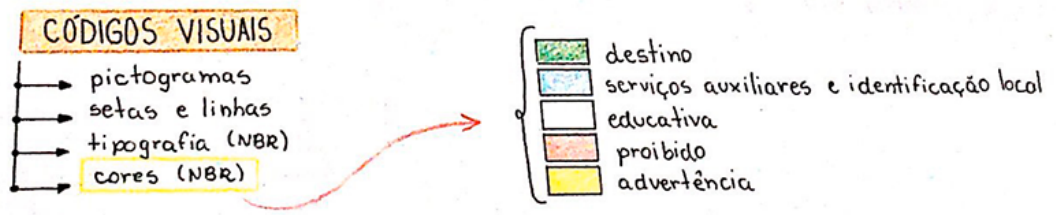


Como parâmetros de análise, foram constituídos os seguintes a partir de um levantamento de dados:

- Presença de texto reduzido e sintético;

- Simplicidade pragmática: padrão de leitura ocidental;

- Ordenação por tamanho de texto;

- Diferenciação por cor;

- Simplicidade sintática;

- Ilustrações simplificadas;

- Ilustrações conectam com o tema;

- Separação por containers;

- Conexão por conectores;

- Noção de temporalidade.

\section{Análise e discussão das amostras selecionadas}

A amostra 1 apresenta capacidade de síntese, texto em caixa alta e segue o padrão de leitura ocidental. As ilustrações contextualizam o tema e são simplificadas a linhas, contornos e traços. As imagens são separadas pelos conectores, referenciando a temporalidade. Há aplicação de poucas cores, que separam por hierarquia.

A segunda amostra reduz o conteúdo ao título, alternando caixas e utilizando tópicos. A informação segue o padrão ocidental e as ilustrações são pouco complexas. Algumas possuem preenchimento, outras sombreado. Utilizam cinco cores e estão separadas por agrupamentos, com um container e dois conectores. Não há noção de temporalidade e conexão.

A amostra 3 é organizada no modo ocidental, com containers e conectores sinalizando ordem e sequência. Os conectores não seguem padrão de tamanho ou sentido, dificultando a leitura. O texto é explicativo, reduzido e sintético. Possui informação hierarquizada por tamanho, sem diferenciação de caixa. As imagens seguem a complexidade do tema, coloridas ou preto e branco. As representações são próximas à realidade por se tratar de uma SPP sobre saúde que requer identificação literal do objeto.

Com relação à amostra 4, o texto é reduzido em títulos e tópicos, hierarquizado por tamanho e disposto na leitura ocidental. As ilustrações são simplificadas e possuem quatro cores, que não separam informações. O conteúdo imagético acompanha e traduz o conteúdo e a RGS possui poucos containers, mas os conectores apresentam sequenciamento das informações.

A amostra 5 possui conteúdo reduzido, cuja síntese é representada em listas e tópicos no sentido ocidental. Apresenta ilustrações simplificadas que se relacionam com o conteúdo. Separadas por containers e cores, a presença de conectores é reduzida e não há noção temporal.

A partir das análises, foi possível identificar que os alunos tendem a obedecer o padrão ocidental de organização da informação, utilizam cores e diferenciação de caixa tipográfica, bem como variação de tipos para enfatizar e hierarquizar informações. Nota-se que conectores e containers poderiam ser melhor explorados. 


\section{Considerações finais}

Reconhecer como as representações gráficas de síntese podem ser utilizadas para ilustrar o pensamento visual é um tema de relevância para a academia e para o Design da Informação. Assim, concluiu-se que os aspectos aqui abordados atendem às representações gráficas geradas a partir de visual thinking, visual learning e visual communication, identificando ferramentas empregadas na representação gráfica do pensamento visual e verificando a maneira como o aluno formaliza o pensamento visual para exercícios e fixação de conteúdos.

Embora prevista verificação da aplicabilidade do modelo na condução de representações junto aos alunos, esta etapa não foi realizada em virtude da pandemia do COVID-19, impossibilitando o contato pessoal, bem como procedimentos previstos como focus group e teste de compreensão. Apesar disso, admite-se a necessidade em configurar formalmente um modelo que considere aspectos semióticos em desdobramentos futuros desta pesquisa. Dessa maneira, seria importante dar continuidade ao projeto em momento oportuno para dirimir tais lacunas.

\section{Referências}

Alves, G. F., \& Aguiar, M. P. de. (2017). Modelo esquemático para classificação e categorização sintática da infografia impressa. InfoDesign - Revista Brasileira De Design Da Informação, 14(2), 273-284. https://doi.org/10.51358/id.v14i2.607

Barton, B. F., \& Barton, M. S. (1987). Simplicity in Visual Representation: A Semiotic Approach. lowa State Journal of Business and Technical Communication, 1(1), 9-26. https://doi.org/10.1177/105065198700100103

Bueno, J., Padovani, S., \& Smythe, K. C. A. S. (2017). Representações gráficas de síntese (RGSs): proposta de um modelo de avaliação. InfoDesign - Revista Brasileira De Design Da Informação, 14(2), 187-203. https://doi.org/10.51358/id.v14i2.608

Engelhardt, Y. (2002). The language of graphics : a framework for the analysis of syntax and meaning in maps, charts and diagrams. Universiteit van Amsterdam.

Maia, T. (2005). Conteúdo ou forma? Um estudo sobre a influência da familiaridade com a linguagem pictórica e o conteúdo informacional na compreensão de sequência pictórica de procedimento. Infodesign - Revista Brasileira de Design da Informação, 2(1), 34-38. https://doi.org/10.51358/id.v2i1.17

Masini, E. F. S., \& Moreira, M. A. (2008). Aprendizagem significativa: condições para ocorrência e lacunas que levam a comprometimentos. São Paulo: Vetor.

Neves, Dulce Amélia. (2006). Ciência da informação e cognição humana: uma abordagem do processamento da informação. Ciência da Informação, 35(1), 39-44. https://doi.org/10.1590/S0100-19652006000100005

Padovani, S. (2012). Representações gráficas de síntese: artefatos cognitivos no ensino de aspectos teóricos em design de interfaces. Educação Gráfica, (16), 123-142.

Padovani, S., Bueno, J., \& de Oliveira, J. F. (2020). Representações Gráficas de Síntese (RGS): em busca de uma elucidação do conceito. InfoDesign - Revista Brasileira De Design Da Informação, 17(1), 131-151. https://doi.org/10.51358/id.v17i1.738 
Pettersson, R. (2002). Information Design: an Introduction. Amsterdam: John Benjamins Publication.

\section{Sobre as autoras}

Fernanda P. Corrêa da Silva, Bel., UP, Brasil.<pcs.fernanda@gmail.com>

Michelle Pereira de Aguiar, Dra., UP, Brasil.<michelle.aguiar@up.edu.br> 